\title{
REMODELAGEM DAS VARIÁVEIS ANIMACIDADE, GRAU E FORMALIDADE LÉXICA DOS SUBSTANTIVOS: O PROCESSO DE CONCORDÂNCIA NOMINAL - SANTA LEOPOLDINA/ES
}

RESUMO: Este artigo é produto da dissertação de Lopes (2014), que analisa o fenômeno da concordância nominal de número, no português falado, na zona rural do município de Santa Leopoldina, região serrana do estado do Espírito Santo. Na amostra, perfez-se 6313 dados, mediante uma análise de cunho atomístico do sintagma nominal - ou seja, cada elemento do sintagma nominal é considerado passível de análise. A pesquisa culminou em uma taxa geral de $61,3 \%$ de concordância nominal. Este texto visa apresentar, especificamente, o efeito da variável animacidade, grau e formalidade léxica dos substantivos na comunidade sob análise. Estudo pioneiro, acerca da concordância nominal, a obra de Scherre (1988) analisa as variáveis "animacidade dos substantivos" e "grau e formalidade léxica dos substantivos e adjetivos" como dois grupos de fatores diferentes. Em Santa Leopoldina, essas variáveis tiveram de ser remodeladas, a partir de sua amalgamação, visto que a análise dessas em separado não produzia convergência estatística, fator que aponta para a existência de ortogonalidade entre essas, como atesta Guy e Zilles (2007). Diante disso, discutiremos os resultados das variáveis analisadas separadamente e amalgamadas. Nosso objetivo é refletir sobre as motivações dos resultados leopoldinenses. A este respeito, Lopes (2014, p. 177) observa que itens [- humano] e [+ animado], independentemente do grau e formalidade, desfavorecem a presença de marcas nesta comunidade. Diante disso, nossa hipótese é que o fato desses elementos serem integrados ao cotidiano campestre em Santa Leopoldina favorece a intimidade o falante e o elemento a ser flexionado, o que desfavorece a concordância nominal.

PALAVRAS-CHAVE: animacidade, grau e formalidade léxica dos substantivos, concordância nominal, Santa Leopoldina.

\section{Considerações iniciais}

O presente estudo trata do fenômeno de concordância nominal de número, realizado na zona rural do município de Santa Leopoldina, localizado na Região Serrana, do estado do Espírito Santo. A ancoragem teórica das análises ora divulgados subjazem das contribuições de Weinrinch, Labov e Herzog (2006) e Labov (2008 [1972]), no que tange

* Mestre em Linguística pela Universidade Federal do Espírito Santo (Ufes). Doutoranda em Linguística pela mesma Universidade. 
à Sociolinguística Variacionista, doravante Teoria da Variação ou Sociolinguística Laboviana.

De acordo com Labov (2008 [1972], p. 242), a questão sociolinguística fundamental é suscitada pela necessidade de se compreender porque o falante diz determinada coisa. Labov (2008 [1972]) salienta ainda que:

Para lidar com a lingua, temos de olhar para os dados da fala cotidiana o mais perto e diretamente possível, e caracterizar seu relacionamento com as teorias gramaticais de modo mais acurado que pudermos, corrigindo e adequando a teoria para que ela se ajuste ao objetivo visado. (p. 236)

Dessa maneira, compreendemos que o entendimento sociolinguístico de estudo da língua pressupõe uma análise intrinsicamente relacionada à fala cotidiana. Esse pensamento desnuda uma premissa do pensamento sociolinguístico que se baseia na ideia de que a variação e a mudança linguística se relacionam à comunidade de fala.

Essa ponderação inicial justifica o fato recorrentes linguistas retomarem o estudo da concordância nominal de número em diferentes comunidades. As primeiras análises sobre o tema, no português brasileiro, remontam do final da década de 70 e 80 , com as obras de Braga (1977) - Triângulo Mineiro; Scherre (1978) - Rio de Janeiro; Guy (1981) Rio de Janeiro; Scherre (1988) - Rio de Janeiro.

O estudo em Santa Leopoldina, no entanto, faz parte de um grupo de mais restrito de publicações, ao lado de obras como a de Dias (1993), visto que tem como objeto de estudo o português falado na zona rural do município. A análise leopoldinense é de cunho atomístico, ou seja, considera cada item do sintagma nominal como um termo passível a ser codificado. Vejamos a exemplificação a seguir de dados retirados da amostra em questão:

Exemplo:

Entrevistador - [...] E você ajuda seus pais?

Informante - Tem vez eu ajudo na limpada da casa um pouquinho.

$E-E ́$ ? Você faz o quê?

Inf- Varro um pouquinho, limpo os móvel.

$E-E$ você sabe varre, ou senão a mãe quando chega tem que varrer tudo de novo? Inf-Eu sei. 
E - Você sabe direitinho!? E o que mais você faz para ajudar sua mãe? Inf-Limpo os móveis.

(feminino, ensino fundamental 01, 07-14 anos)

Fonte: Amostra de Santa Leopoldina, de Foeger (2014) e Lopes (2014)

Neste exemplo, é possível perceber que os dois sintagmas, em destaque, contêm dois itens a serem analisados pelo linguista: sintagma 01 - os, móvel; sintagma 02 - os, móveis. Note que o mesmo falante transita entre a forma padrão e a não padrão de marcação de plural. A amostra leopoldinense em análise conta com um total de 32 entrevistas, composta a partir da colaboração de 32 voluntários estratificados em: (i) sexo - feminino e masculino; (ii) faixa etária - 07-14, 15-25, 26-49 e acima de 49 anos; escolaridade, nota-se uma discrepância entre as amostras; (iii) escolaridade - ensino fundamental 01 e 02 . Para análise estatística dos dados, utilizamos o programa computacional Gold Varb X, de Sankoff, Tagliamonte e Smith (2005).

No estudo na íntegra, proposto por Lopes (2014), são analisadas as seguintes variáveis de estudo: sociais - sexo, faixa etária e escolaridade; linguística - saliência fônica, posição linear e relativa do sintagma nominal, marcas precedentes, grau e formalidade dos substantivos e adjetivos e, por fim, animacidade dos substantivos. Em um primeiro momento, a linguista apresenta a análise das variáveis grau e formalidade dos substantivos e adjetivos e animacidade dos substantivos em separado. Todavia, observa que a convergência na rodada geral não foi obtida. Analisando os resultados obtidos nesta rodada, concluise que havia falta de ortogonalidade entre essas duas variáveis, o que culminava na ausência de convergência. Essa situação foi resolvida ao realizar a amalgamação das duas variáveis, o que ocasionou resultados convergentes e com significância estatística.

Neste texto, discorremos, inicialmente, sobre Santa Leopoldina, de forma a evidenciar as motivações para a realização do estudo nesta comunidade. Sendo assim, no próximo tópico, apresentaremos alguns dados estatísticos importantes do Instituto Brasileiro de Geografia e Estatística (IBGE), tal como observações adquiridas em nosso período de pesquisa em campo. Em seguida, ressaltaremos dados metodológicos relevantes para a composição da amostra leopoldinense e análise de dados. Sequente, apresentaremos os resultados observados em Santa Leopoldina. Nosso objetivo é refletir sobre os números obtidos 
à luz das particularidades da comunidade em estudo. Por fim, algumas considerações serão apresentadas.

\section{Santa Leopoldina: por que esta comunidade?}

A escolha por Santa Leopoldina não ocorreu aleatoriamente. Nossa estratégia inicial era, na obra de Lopes (2014), realizar um contraponto entre os resultados da comunidade mais rural do estado do Espírito Santo, com os dados da capital Vitória. Isso seria possível a partir da realização de um estudo comparativo entre os dados leopoldinenses e o de Silva $(2011,2013)^{1}$.

Isso porque, os dados divulgados pelo IBGE, por meio do Censo de 2010, atestam que Vitória é o único município que possui a totalidade de seus habitantes em zona urbana. Mediante a análise dos resultados do censo, percebemos ainda que Santa Leopoldina figura como o município capixaba com maior percentual de habitantes moradores da zona rural. Vejamos os dados do IBGE (2010):

Tabela 01 - Dados do Censo IBGE/2010 - Vitória

\begin{tabular}{|c|c|c|}
\hline Município & Total da população rural & Percentagem \\
\hline Santa Leopoldina & 9.621 & $78,51 \%$ \\
\hline Domingos Martins & 24.083 & $75,68 \%$ \\
\hline Brejetuba & 8.504 & $71,34 \%$ \\
\hline Município & $\begin{array}{c}\text { Total da população } \\
\text { urbana }\end{array}$ & Percentagem \\
\hline Vitória & 325.453 & $900 \%$ \\
\hline Vila Velha & 412.402 & $99,31 \%$ \\
\hline Serra & 406.517 & $91 \%$ \\
\hline
\end{tabular}

Fonte: Disponível em http://censo2010.ibge.gov.br. Acesso em 27/10/11 - adaptada

${ }^{1}$ Os trabalhos de Silva (2011 e 2013) propõe o estudo da concordância nominal, na capital Vitória/ES, com dados de 43 entrevistas que integram o total de 46 entrevistas do Projeto de "O Português Falado na Cidade de Vitória" 
Lopes (2014) estabelece ainda algumas comparações entre os dados leopoldinenses e os resultados pioneiros de Scherre (1988). Neste artigo, no entanto, reservaremos nossas considerações às observações da fala rural de Santa Leopoldina, embora, por vezes, façamos algumas referências a outras obras. Essa metodologia justifica-se pelo fato de não se ter notícia, até o momento, de estudos que abordem a variável animacidade, gran e formalidade léxica dos substantivos, tal como sistematizada por Lopes (2014) e apresentada neste texto. Por isso, no título dessa obra, esclarecemos que se trata de uma remodelagem dos grupos de fatores animacidade dos substantivos e grau e formalidade léxica dos substantivos e adjetivos, visto que o tratamento estatístico desses, tal como realizados em outras bibliografias, não se mostrou adequado para a comunidade em estudo.

Esse quadro reflete as particularidades da comunidade leopoldinense. Anteriormente denominada Cachoeiro de Santa Leopoldina, no início da colonização capixaba, a região tinha muito destaque, em decorrência de sua localização estratégica para o escoamento da mercadoria vindas da Metrópole, como retrata o site institucional da Prefeitura de Santa Leopoldina:

Com os primeiros ranchos de tropa, armazéns de carga e postos de abastecimento, surgiu o Porto de Cachoeiro que, em 1867, tornouse a Sede Oficial da Colônia com a denominação de Cachoeiro de Santa Leopoldina. Deu-se o nome de Cachoeiro devido sua localização da Sede, que se encontrava no local onde o rio deixava de ser encachoeirado. E durante mais ou menos cinquenta anos, o movimento de exportação e importação foi firmemente mantido em animado ritmo. Cachoeiro de Santa Leopoldina chegou a ser a $3^{\mathrm{a}}$ colônia mais populosa do império. O comércio intenso e o casario ao gosto neoclássico que se erguia fizeram com que, em 1882, a colônia se emancipasse. (Disponível em: http://www.santaleopoldina. es.gov.br/. Acesso em 12/09/13 - adaptado)

Esse tempo áureo era devido à localização estratégica do Rio Santa Maria, que promovia a facilidade no transporte fluvial. Todavia, em 1930, ao se construir as primeiras 
estradas de rodagem ligando Santa Leopoldina² com a capital: “Ao contrário do que se imaginava, apagaram-se os dias de glória e esplendor, pois o esteio da economia era o Rio Santa Maria da Vitória e não a rodovia como se supunha" (Disponível em: http://www.santaleopoldina.es.gov.br/. Acesso em 12/09/13).

Atualmente, o município permanece de base agrícola. De acordo com dados do Programa de Assistência Técnica e Extensão Rural (PRONATER/ 2011-2013), do Incaper, Santa Leopoldina possui 2.605 propriedades, das quais: 1.383 são minifúndios; 1.067, pequenas; 143, médias; 12, grandes. Diante disso, concluímos que a estrutura fundiária leopoldinense, portanto, é de base familiar, sendo o trabalho realizado pela própria família ou por um sistema de parceria agrícola. Dos 6.762 hectares (ha) aptos ao plantio 5.545 ha são destinados ao cultivo da banana e do café, que ocupam 1.215 ha e 4.330 ha, respectivamente. Sendo os demais produtos cultivados - gengibre, laranja, inhame, feijão, dentre outros - direcionados ao consumo familiar ou a transações comerciais menores. A comercialização dos produtos ocorre na Central de Abastecimento do Espírito Santo (CEASA), localizada em Cariacica, região Metropolitana da Grande Vitória.

\section{Metodologia de pesquisa}

A amostra leopoldinense é composta por um total de 32 entrevistas, cedidas por 32 habitantes da zona rural do município. Para seleção desses voluntários, estabelecemos os seguintes critérios: o falante deveria ser natural de Santa Leopoldina e residente da zona rural do município; não poderia ter se afastado da região por mais de um terço de sua vida; ter pais e cônjuges leopoldinenses; não falar outra língua, além do português.

Os informantes foram estratificados em: sexo - feminino e masculino; faixa etária - 07-14, 15-25, 26-49 e acima de 49 anos; escolaridade - ensino fundamental 01 e 02. Vejamos no quadro 01, a disposição dos 32 informantes, em função dos fatores sociais analisados:

\footnotetext{
${ }^{2}$ Nos anexos A e B, dispomos, respectivamente mapa de infraestrutura de transporte - municípios adjacentes a Santa Leopoldina/ES - limite territorial e da divisão territorial do município. A intenção é que nosso leitor conheça um pouco da região sob análise.
} 
Quadro 01: Fatores sociais analisados e distribuição dos informantes em células

\begin{tabular}{|l|c|c|c|c|c|c|c|c|r|}
\hline Faixa Etária & \multicolumn{2}{|c|}{$\mathbf{0 7 - 1 4}$} & \multicolumn{2}{c|}{$\mathbf{1 5 - 2 5}$} & \multicolumn{2}{c|}{$\mathbf{2 6 - 4 9}$} & \multicolumn{2}{c|}{$\mathbf{7 4 9}$} & TOTAL \\
\hline Sexo & $\mathrm{F}$ & $\mathrm{M}$ & $\mathrm{F}$ & $\mathrm{M}$ & $\mathrm{F}$ & $\mathrm{M}$ & $\mathrm{F}$ & $\mathrm{M}$ & \\
\hline Ensino Fundamental I & 2 & 2 & 2 & 1 & 2 & 2 & 2 & 2 & $=15$ \\
\hline Ensino Fundamental II & 2 & 2 & 2 & 3 & 2 & 2 & 2 & 2 & $=17$ \\
\hline
\end{tabular}

Fonte: Lopes, 2014, p. 65 - adaptado

A coleta da amostra ocorreu em forma de entrevistas, nos termos de Labov (2008), com duração média de 50-60 minutos, e seguia um roteiro flexível de perguntas previamente estruturadas pelos entrevistadores. A composição da amostra é resultado da união dos esforços de Camila Candeias Föeger e Lopes, quando no mestrado, sob orientação das professoras Lilian Coutinho Yacovenco e Maria Marta Pereira Scherre, respectivamente.

Após a gravação das entrevistas, a transcrição era realizada sem o auxílio de programa computacional para transcrição, utilizando apenas programas de áudio - Media Player - e de digitação - Microsoft Word. No que se refere às análises estatísticas, a codificação dos dados e seus respectivos resultados eram obtidos por meio do programa GoldVarb X (SANKOFF; TAGLIAMONTE; SMITH, 2005) - ferramenta adequada a análises de fenômenos variáveis, tal como a concordância nominal de número.

O conjunto da obra de Lopes (2014), em um primeiro momento, analisa variáveis sociais - sexo, faixa etária e escolaridade - e linguísticas - posição linear e relativa, saliência fônica, marcas precedentes, grau de formalidade dos substantivos, animacidade dos substantivos. Posteriormente, a sistematização dos dados culminou em análises cruzadas dos fatores sociais e na amalgamação das duas últimas variáveis linguísticas citadas, o que promoveu a remodelagem dessas no grupo animacidade, grau e formalidade léxica dos substantivos. No presente estudo, no entanto, conforme mencionado anteriormente, restringiremos nossas considerações à variável animacidade, grau e formalidade léxica dos substantivos, de forma a evidenciar as particularidades dos grupos analisados separadamente e após a amalgamação. 


\section{Análise da amostra}

$\mathrm{Na}$ análise da amostra de Santa Leopoldina, perfez-se 6313 dados, dos quais 3873 termos eram marcados quanto à pluralidade pelo informante, o que culminou em um percentual de marcação de $61,3 \%$. Nesses dados gerais estão inclusos todos os itens passíveis de variação, cita-se: determinantes, adjetivos e substantivos. Entretanto, na análise do grupo de fatores grau de formalidade dos substantivos e adjetivos, os determinantes foram retirados da estatística, gerando um total de 3144 dados codificados, dos quais 903 itens, ou seja, um $28,7 \%$ foram marcados pelo falante. No que se refere à animacidade dos substantivos, determinantes e adjetivos foram subtraídos da rodada, totalizando, portanto, 2797 dados, sendo desses 777 vocábulos, portanto, 27,8\% retiveram a marca de plural.

Essa primeira etapa de análise orientou-se pelas estratégias metodológicas adotadas por Scherre (1988), no que se refere à categorização dos itens. Vejamos na tabela sequente, fatores analisados, sua respectiva exemplificação, resultados em percentagem e em peso relativo - frisamos que esses resultados foram obtidos com base em uma mesma rodada, sem convergência, e são anteriores a amalgamação desses grupos de fatores:

Tabela 02: Efeito das variáveis grau e formalidade dos substantivos e adjetivos e animacidade dos substantivos no português falado na zona rural de Santa Leopoldina/ES.

\begin{tabular}{|c|c|c|c|}
\hline \multicolumn{4}{|c|}{ Animacidade dos substantivos } \\
\hline Fatores analisados & Exemplos & Percentagem & PR \\
\hline [- humano] e [- animado] & $\begin{array}{l}\text { os carros } \\
\text { (fem, fund2, 53anos) }\end{array}$ & $522 / 1911=27,3 \%$ & {$[0,51]$} \\
\hline [- humano] e [+ animado] & $\begin{array}{l}\text { os porco é a meia com o } \\
\text { (fem, fund } 1,72 \text { anos) }\end{array}$ & $20 / 100=20 \%$ & {$[0,29]$} \\
\hline [+ humano] e [- coletivo] & $\begin{array}{l}\text { eles eram.... cinco irmão } \\
\text { (masc, fund1, } 12 \text { anos) }\end{array}$ & $235 / 786=29,9 \%$ & {$[0,50]$} \\
\hline TOTAL & & \multicolumn{2}{|c|}{$7757 / 2797=27,8 \%$} \\
\hline$R A N G E$ & & 22 & \\
\hline \multicolumn{4}{|c|}{ Grau e formalidade dos substantivos e adjetivos } \\
\hline Fatores analisados & Exemplos & Percentagem & PR \\
\hline $\begin{array}{l}\text { 1. Grau diminutivo ou au- } \\
\text { mentativo - mais informal }\end{array}$ & $\begin{array}{l}\text { nesses morrão aí.. } \\
\text { (fem, fund } 2,55 \text { anos) }\end{array}$ & $23 / 155=14,8 \%$ & {$[0.32]$} \\
\hline $\begin{array}{l}\text { 2. Grau normal - mais in- } \\
\text { formal }\end{array}$ & $\begin{array}{l}\text { essas coisas assim... } \\
\text { (fem, fund } 1,39 \text { anos) }\end{array}$ & $98 / 495=19,8 \%$ & {$[0.41]$} \\
\hline $\begin{array}{l}\text { 3. Grau normal - menos in- } \\
\text { formal }\end{array}$ & $\begin{array}{l}\text { uns doze quilômetro } \\
\text { (masc, fund1, } 12 \text { anos) }\end{array}$ & $782 / 2494=31,4 \%$ & {$[0.53]$} \\
\hline TOTAL & & \multicolumn{2}{|c|}{$903 / 3144=28,7 \%$} \\
\hline$R A N G E$ & & \multicolumn{2}{|l|}{21} \\
\hline
\end{tabular}

Fonte: Lopes, 2014, p. 138 e 140 - adaptada 
Scherre (1988) controla ainda, na variável animacidade dos substantivos, os itens [+ humano] e [+ coletivo], do tipo:

Exemplo:

Informante - não... assim que eu casei eu fui crente então na religião crente... hoje eu não sei porque hoje eu sou católica né? mas naquele tempo a igreja crente tinha os seus grupo de criança... de jovem... tudo assim...

(fem, fund 01,72 anos)

Fonte: Amostra de Santa Leopoldina, de Foeger (2014) e Lopes (2014))

A sistematização do efeito desses itens não foi possível, em Santa Leopoldina, visto que, conforme esclarece Lopes (2014), obteve-se um total de 11 ocorrências com esse perfil, sendo todas categoricamente não marcadas quanto à pluralidade. Quanto aos dados apresentados na tabela 02 , nota-se que os pesos relativos estão entre colchetes, essa formatação se justificava para sinalizar que esses resultados foram obtidos a partir de uma rodada sem convergência. Quanto a isso, Lopes (2014) destaca que:

orientamos nossa análise a partir do observado por outros estudiosos, como Scherre (1988), ou seja, a princípio, codificamos essas variáveis em separado. Contudo, nossos dados produziam rodadas sem convergência, inclusive a rodada geral. Percebemos, por fim, que se retirássemos uma das variáveis citadas, a convergência era obtida. Dessa forma, concluímos que havia sobreposição, em algum grau, entre essas variáveis. Assim, amalgamamos essas em um grupo maior. (p. 136-137)

Essas considerações acerca da ausência da convergência encontram-se baseadas nas ponderações de Guy e Zilles (2007). Neste artigo, portanto, apresentaremos os dados das duas rodadas: (i) sem convergência, conforme tabela 02; e (ii) com convergência - na tabela 03.

No que se refere aos dados apontados na tabela 02 , notamos que, quanto ao grupo de fatores grau e formalidade dos substantivos e dos adjetivos, este segue a mesma tendência observada por Scherre (1988). Percebemos que os itens mais informais independentemente do grau do substantivo ou adjetivo tendem a desfavorecer a marcação de plural. Observamos, no entanto, que considerada a ordenação interna dos fatores, os termos em grau normal - 
menos informal, com 0,530 de peso relativo, apresentam um leve favorecimento a marcação da concordância.

Quanto à variável animacidade dos substantivos, os itens [- humano] e [-animado] e [+ humano] e [- coletivo] demonstram pesos relativos semelhantes, em 0,51 e 0,50. Dessa forma, diferente dos resultados de Scherre (1988), que apontavam para o favorecimento dos itens [+ humanos], em Santa Leopoldina, não podemos concluir que este traço é imprescindível para a (não)marcação dos itens. Por outro lado, os itens [- humano] e [+ animado] tendem a desfavorecer a marcação do plural. A este respeito, Lopes (2014) reflete que:

A categoria [- humano] e [+ animado], portanto, desfavorece a marcação, tendo 20 dados marcados de um total de 100 ocorrências. Nesse fator, aparecem, predominantemente, espécies de animais pertencentes ao cotidiano da comunidade. Nossa hipótese é que o contato dos falantes leopoldinenses com esses elementos, em seu cotidiano, instaure certa intimidade com esses vocábulos. Propomos que essa intimidade se reflita na fala através da ausência de marcação de plural. (p. 141)

Esclarecemos que essa pontuação será retomada na apresentação dos dados convergentes. Vejamos a seguir resultados provenientes da rodada com a amalgamação das variáveis, que promoveu a remodelagem dessas em animacidade, gran e formalidade léxica dos substantivos.

Tabela 03: Efeito da variável animacidade, gran e formalidade léxica dos substantivos, no português falado na zona rural de Santa Leopoldina/ES

\begin{tabular}{|l|c|r|}
\hline Fatores analisados & Percentagem & Peso relativo \\
\hline [-humano] e [+ animado] e diminutivo/aumentativo mais informal & $02 / 25=7,4 \%$ & 0,154 \\
\hline [+ humano] e [- coletivo] e diminutivo/aumentativo mais informal & $01 / 10=10 \%$ & 0,256 \\
\hline [-humano] e [+ animado] e grau normal menos informal & $18 / 72=25 \%$ & 0,323 \\
\hline [-humano] e [- animado] e diminutivo/aumentativo mais informal & $20 / 105=19 \%$ & 0,356 \\
\hline$[$-humano] e [- animado] e grau normal mais informal & $59 / 371=15,9 \%$ & 0,374 \\
\hline [+ humano] e [- coletivo] e grau normal mais informal & $05 / 26=19,2 \%$ & 0,416 \\
\hline [+ humano] e [- coletivo] e grau normal menos informal & $229 / 750=30,5 \%$ & 0,535 \\
\hline [-humano] e [- animado] e grau normal menos informal & $443 / 1435=30,9 \%$ & 0,546 \\
\hline [-humano] e [+ animado] e grau normal mais informal & ---- & ---- \\
\hline TOTAL & $\mathbf{7 7 7 / 2 7 9 6 = 2 7 , 8} \mathbf{0}$ \\
\hline $\boldsymbol{R A N G E}$ & $\mathbf{4 0}$ \\
\hline
\end{tabular}

Fonte: Lopes, 2014, p. 145 
Neste ponto, é importante sinalizar os valores dos ranges obtidos pelas três variáveis, nas duas rodadas em análise. A este respeito, cedemos a palavra a Tagliamonte (2009) que afirma que:

A força é medida pelo range, que é então comparado com os intervalos dos outros grupos fatores significativos. O range é calculado subtraindo-se o menor peso do fator de maior peso. Quando estes números são comparados em cada um dos grupos de fatores de uma análise, os números mais elevados identificam a restrição mais forte. (p. 242)

Diante disso, notamos que o valor do range aponta para a força de restrição da variável sob análise. Concluímos, portanto, que, na primeira rodada, sem convergência, a análise das variáveis em separado grau e formalidade dos substantivos e adjetivos e animacidade dos substantivos representam, respectivamente, 21 e 22 pontos de ranges. Esses valores inferiores ao observado, na segunda rodada, para a remodelagem das variáveis animacidade, grau e formalidade léxica dos substantivos que atesta 40 pontos de range. Isso indica, conforme esperado, que, na segunda rodada, com convergência, a variável remodelada apresenta maior força de restrição, no que se refere ao fenômeno da concordância nominal de número, em Santa Leopoldina/ES.

No gráfico 01, apresentamos a ordenação dos pesos relativos dos fatores analisados, por meio dela é possível ter uma percepção mais clara do comportamento dos itens em Santa Leopoldina. Vejamos:

Gráfico 01: Efeito da variável animacidade, grau e formalidade léxica dos substantivos, no português falado na zona rural de Santa Leopoldina/ES

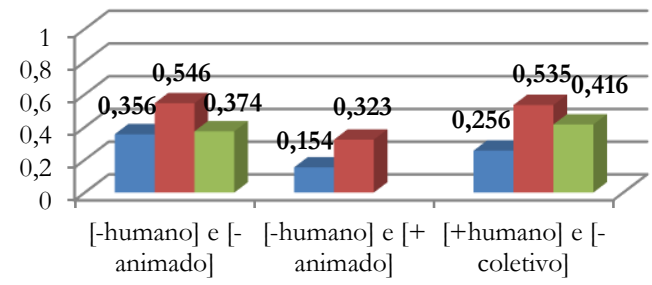

- Diminutivo/aumentativo Grau normal menos informal

Grau normal mais informal

Fonte: Lopes, 2014, p. 146 
Os presentes resultados confirmam a hipótese de que os itens designadores de animais tendem a desfavorecer a aplicação da marcação de plural. Notamos, portanto, que os vocábulos com o perfil [- humano] e [+ animado], independentemente do grau e da formalidade léxica - seja em grau diminutivo/aumentativo ou em grau normal menos informal - tendem a desfavorecer a marcação com 0,154 e 0,323 de peso relativo, respectivamente. Nesse sentido, parece que, por estes termos serem pertencentes ao cotidiano da comunidade, o falante desenvolve certa familiaridade/intimidade com esses vocábulos, o que promove a ausência de marcação. Todavia, Lopes (2014, p. 147) pondera que, seria interessante aplicar essa metodologia a outros contextos da vida leopoldinense, tal como formas de plantio dos alimentos cultivados na região, na intenção de perceber se a tendência de menos marcação também se aplica entre esses itens.

Quanto aos itens [- humano] e [- animado], percebemos que os vocábulos em grau diminutivo/aumentativo e em grau normal mais informais possuem pesos relativos semelhantes, em 0,36 e 0,37 , respectivamente. Isso indica que a formalidade é determinante a marcação, visto que, conforme destaca Scherre (1988), os itens em grau diminutivo/aumentativo são reconhecidamente mais informais. Essa ideia é comprovada mediante a observância do comportamento dos [- humano] e [- animado] em grau normal menos informal, os quais apresentam o maior peso relativo de todo o grupo de fatores.

Essa tendência de marcação dos itens menos informais também é observada entre os [+ humano] e [- coletivo], haja vista que essa categoria apresenta o segundo maior peso relativo entre os fatores da variável remodelada em 0,535. Seguido dos termos [+ humano] e [- coletivo] em grau normal mais informal, com 0,416. Destaque ainda aos termos dessa categoria em grau diminutivo/aumentativo que evidenciam peso relativo de 0,256.

Analisando o conjunto dos dados dessa variável, ainda no que se refere à hipótese da intimidade entre os elementos [- humano] e [+ animado], e Lopes (2014) salienta que:

Notamos que o comportamento dos termos [- humano] e [- animado] e [+ humano] e [- coletivo] em grau normal e menos informais têm comportamento semelhante com 0,546 e 0,535 , respectivamente. Inferimos que esses itens seguem a mesma tendência, ou seja, favorecem a marcação da concordância. Diferentemente, os 
itens em grau normal e menos informais do fator [- humano] e [+ animado] desfavorecem a aplicação da marca, com 0,323 de peso relativo. Isso sustenta nossa hipótese do grau de intimidade desses elementos com a comunidade influenciar no processo de marcação. (p. 147)

Diante disso, podemos concluir que a remodelagem das variáveis animacidade dos substantivos e grau e formalidade léxica dos substantivos e adjetivos instiga ainda novas análises, o que assegura o prosseguimento da pesquisa ora apresentada.

\section{Considerações finais}

É interessante observar que nossos dados, em certa medida, apresentam uma nova perspectiva de análise da concordância nominal de número. A metodologia adotada foi possível em decorrência da atenção do linguista dada à comunidade. Nesse sentido, a não obtenção da convergência mostrou-se algo positivo, visto que foi o ponto de partida para adoção de um viés de análise remodelado das variáveis animacidade dos substantivos e grau $e$ formalidade léxica dos substantivos e adjetivos.

Essa observação reforça a ponderação Alkmim (2011) que ressalta que: "toda língua é adequada à comunidade que a utiliza, é um sistema completo que permite a um povo exprimir o mundo físico e simbólico em que vive” (p. 41). Concluímos, portanto, que embora o estudo do fenômeno de concordância nominal de número no português brasileiro tenha sido explorado por diversos linguistas em diferentes comunidades de fala, isso não invalida a relevância da sistematização desses em novas comunidades, em especial as localizadas em zonas rurais.

Quanto à sistematização das variáveis sob análises, no presente artigo, asseguramos que o grupo de fator remodelado apresenta índices interessantes à análise sociolinguística. O que nos permite concluir que:

Animacidade e grau e formalidade dos substantivos: percebemos que, em Santa Leopoldina, a análise dessas variáveis separadas não era suficiente para o entendimento completo do fenômeno. Verificamos que a frequência de utilização dos vocábulos, mais uma vez, é preponderante no processo de marcação do SN. Além disso, o reconhecimento de um elemento como pertencente à comunidade ou ao seu cotidiano reflete-se na fala dos indivíduos. Isso porque os 
itens [- humano] e [ + animado], ou seja, designadores de animais típicos do ambiente rural, independentemente do grau, desfavorecem a presença de marcas. Concluímos, portanto, que a formalidade de um termo se relaciona com o grau de intimidade entre o falante e o elemento a requerer a pluralização, assim como com a frequência de uso do item. Essa hipótese é confirmada pelo fato de a obtenção da convergência ter sido possível a partir da amalgamação das variáveis animacidade e grau e formalidade dos substantivos. (LOPES, 2014, p. 177)

Ressaltamos que, após a divulgação dos resultados obtidos em Lopes (2014), o processo da concordância nominal de número ainda continua sob análise, na pesquisa atual de linguista Lopes, pela Universidade 2014, em nível de 2014. A amostra leopoldinense em seu status atual conta com 44 entrevistas, seguindo a mesma estratificação, no que se refere ao sexo e a faixa etária dos informantes, e acresce à variável social escolaridade o ensino médio. Além disso, a pesquisa ainda sistematiza, concomitantemente, o fenômeno de concordância verbal de terceira pessoa, na comunidade de Santa Leopoldina. Em breve, novas considerações serão apresentadas, as quais permitirão um mais claro vislumbre dos fenômenos sob análise, no que se refere à fala leopoldinense, capixaba e brasileiro.

Esclarecemos que, consideramos o presente texto como um convite para que nosso leitor busque novas leituras, acerca do tema, dada à vastidão das abordagens sociolinguísticas a este respeito. Além disso, esperamos alcançar novos pesquisadores comprometidos com a pesquisa linguística. Essa que figura como um trabalho árduo, mas que nos permite refletir sobre as minuciosidades do nosso português brasileiro: múltiplo, diverso, heterogêneo.

\title{
REMODELING OF THE ANIMACITY, DEGREE AND LEXICAL FORMALITY OF NOUNS: THE NOMINAL AGREEMENT PROCESS - SANTA LEOPOLDINA/ES
}

\begin{abstract}
This article is the product of the thesis of Lopes (2014), which analyzes the phenomenon of nominal number agreement, in spoken Portuguese, in the rural area of the municipality of Santa Leopoldina, in the mountain region of the state of Espírito Santo. In the sample, 6313 data were made, upon an atomistic analysis of the nominal syntagma - that is, each element of the nominal syntagma is considered susceptible to analysis. The survey culminated in an overall rate of $61.3 \%$ nominal agreement. This text aims to present, specifically, the effect of the variable animacity, degree and lexical formality of the nouns in the community under analysis. A pioneering study on nominal agreement, Scherre (1988) analyzes the variables "animacity of nouns" and "degree and lexical for-
\end{abstract}


mality of nouns and adjectives" as two different groups of factors. In Santa Leopoldina, these variables had to be remodeled, starting from their amalgamation, since the analysis of these separately did not produce statistical convergence, a factor that points to the existence of orthogonality between these, as attested by Guy and Zilles (2007). Therefore, we will discuss the results of the variables analyzed separately and amalgamated. Our goal is to reflect on the motivations of the Leopoldinian results. In this regard, Lopes (2014, p. 177) notes that [- human] and [+ animated] items, regardless of degree and formality, disfavor the presence of brands in this community. Therefore, our hypothesis is that the fact that these elements are integrated into the rural daily life in Santa Leopoldina favors the intimacy, speaker and the element to be inflected, which disfavors the nominal agreement.

KEYWORDS: animacity, degree and lexical formality of nouns, nominal agreement, Santa Leopoldina.

\section{REFERÊNCIAS}

ALKMIM, Tânia Maria. Sociolinguística - parte I. In.: MUSSALIM, Fernanda; BENTES, Anna Christina. Introdução à linguística: domínios e fronteiras. Vol. 01. 9. ed. São Paulo: Cortez, 2011, p. 21-47.

BRAGA, M. L. A concordância de número no sintagma nominal no triângulo mineiro. $1977.88 \mathrm{f}$. Dissertação (Mestrado em Língua Portuguesa) - Universidade Católica do Rio de Janeiro, Rio de Janeiro, 1977.

DIAS, Maria Clara Alvares Correia. A variação na concordância nominal: um contraste entre o urbano e o rural na fala brasiliense. Universidade de Brasília, dissertação de mestrado, 1993.

FÖEGER, Camila Candeias. A primeira pessoa do plural no português falado em Santa Leopoldina/ES. Universidade de Federal do Espírito Santo, dissertação de mestrado, 2014.

GUY, Gregory Riordan. Linguistic variation in Brazilian Portuguese. Tese de Doutorado. University of Pensylvania, 1981.

GUY, Gregory Riordan; ZILLES, Ana. Sociolingüistica quantitativa - instrumental de análise. São Paulo: Parábola Editorial, 2007.

IBGE. Censo Demográfico 2010, Instituto Brasileiro de Geografia e Estatística Cidades - Santa Leopoldina. Disponível em: <http://www.ibge.gov.br/cidadesat/ painel/painel.php?codmun=320 450\#>. Acesso em: 25/02/2013.

INCAPER. Programa de assistência técnica e extensão rural PROATER 2011-2013, Instituto Capixaba de Pesquisa Assistência Técnica e Extensão Rural - Santa Leopoldina. Planejamento e programação de ações (2011). Disponível em: http://www.incaper.es.gov.br/proater/municipios / Centro_cerrano/Santa_Leopoldina.pdf. Acesso em 25/02/2013. 
IJSN. Mapas, Instituto Jones dos Santos Neves. Mapa do Espírito Santo - distância entre Santa Leopoldina-Vitória. Disponível em: http://www.ijsn.es.gov.br. Acesso em: 10/03/2014.

LABOV, William. Padrões sociolinguísticos. Tradução de Marcos Bagno, Maria Marta Pereira Scherre e Cardoso, Caroline Rodrigues. São Paulo: Parábola, 2008 [1972].

LOPES, L. O. J. A concordância nominal de número no português falado na zona rural de Santa Leopoldina. 2014. Dissertação (Mestrado em Estudos Linguísticos) - Programa de PósGraduação em Linguística, Universidade Federal do Espírito Santo, Vitória, 2014. Disponível em: http:/ /linguistica.ufes.br/pt-br/pos-graduacao/PPGEL/detalhes-datese?id=7770. Acesso em: 01/05/2020.

SANKOFF, David; TAGLIAMONTE, Sali A.; SMITH, Elen. Goldvarb X-A multivariate analysis application. Toronto: Department of Linguistics; Ottawa: Department of Mathematics, 2005 http://individual. utoronto.ca/tagliamonte/Goldvarb/GV_index.htm\#ref.

SANTA LEOPOLDINA, História do município. Disponível em: http:/ /www.santaleopoldina.es.gov.br/. Acesso em 25/02/2013.

SCHERRE, Maria Marta Pereira. A regra de concordância de número no sintagma nominal em português. Dissertação de Mestrado. PUC, Rio de Janeiro. 1978, 158p., inédito.

. Reanálise da concordância nominal em português. Tese de Doutorado em Linguística.

Rio de Janeiro, Faculdade de Letras, UFRJ, 1988. Em dois volumes, com 555p. Inédito

SILVA, Janaína Biancardi da. Uma reflexão sobre a concordância nominal na fala capixaba e suas contribuições para o ensino de língua portuguesa. Trabalho de Conclusão de Curso, Ufes, Vitória, 2011.

; SCHERRE, Maria Marta Pereira. A concordância nominal na fala capixaba: fatores sociais. In: CARDOSO, Caroline Rodrigues; SCHERRE, Maria Marta Pereira; LIMA-SALLES, Heloísa Maria Moreira; PACHECO, Cíntia (Orgs.). V ariação linguística, contato de línguas e educação: contribuições do III encontro do grupo de estudos avançados de sociolinguística da Universidade de Brasília. Campinas, SP: Pontes Editores, 2013.

TAGLIAMONTE, Sail A. Analysing Sociolinguistic Variation: key topics in sociolinguistic. $3^{\mathrm{a}}$ ed. New York, Cambridge University Press, 2009.

YACOVENCO, Lilian Coutinho; et all. Projeto Portvix: a fala de Vitória/Es em cena. Alfa: Revista de Linguística (UNESP. Online), v. 56, p. 771-806, 2012.

WEINREICH, Uriel; LABOV, William; HERZOG, Marvin. Fundamentos empíricos para uma teoria da mudança linguística. Tradução de Marcos Bagno. São Paulo: Parábola, 2006 [1968]. 
ANEXO A - Mapa de infraestrutura de transporte - municípios adjacentes a Santa Leopoldina/ES - limite territorial

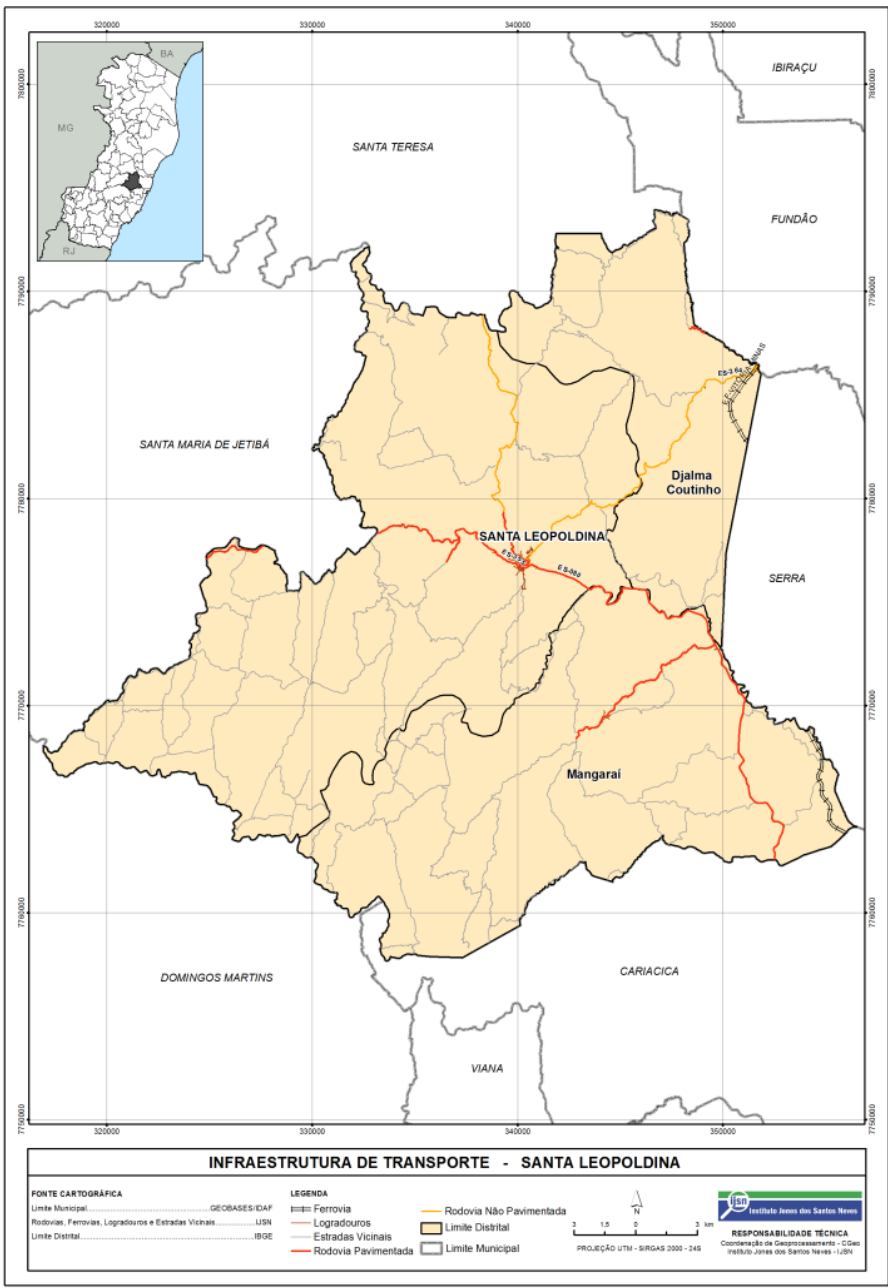

Fonte: Disponível em: http://www.ijsn.es.gov.br/Sitio/custom/mapas/ municipios/geral.php?catid=205. Acesso em: 10 de março de 2014 
ANEXO B - Mapa dos limites administrativos de Santa Leopoldina/ES - divisão territorial do município

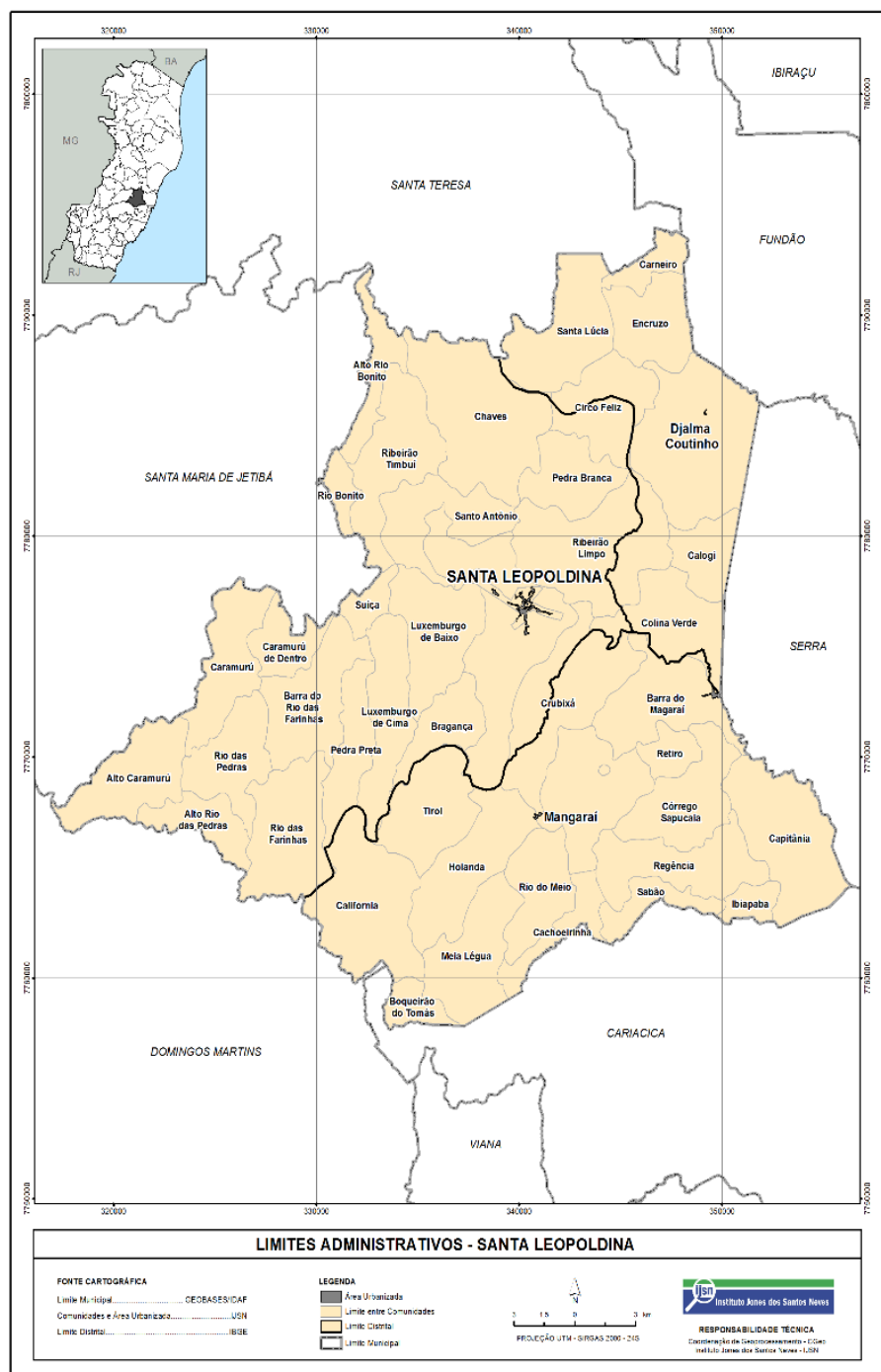

Fonte: Disponível em: http://www.ijsn.es.gov.br/Sitio/custom/mapas/municipios /geral.php?catid=205. Acesso em: 23 de setembro de 2014) 